\section{Lascar Volcano set to erupt?}

SIR-Earlier this year, we showed how short-wavelength infrared observations from remote-sensing satellites can be used to monitor the radiant thermal flux from active volcanoes (L. Glaze et al. Nature 338, 144; 1989), using Lascar volcano, north Chile as our example. We showed that the radiant thermal energy flux had decreased before a phreato-magmatic eruption in September 1986, and had subsequently increased greatly, doubling between October 1986 and November 1987, our last data point.

Reports from Paul King and his colleagues at Minsal, Toconao, Chile, show that a lava dome is now growing in the summit crater of Lascar. When first observed on an ascent of the volcano in February 1989, the lava dome had filled the summit crater to a depth of several tens of metres. The lava dome was absent when the crater was previously observed in January 1987 , but a powerful thermal anomaly on the image we acquired in November 1987 suggests it may have been growing then. Although there are 50-60 major and potentially active volcanoes in the central Andes, many of them over 6,000 metres high, no other lava eruptions have been documented. Lascar is clearly in an unusually active condition, and warrants further monitoring.

Whereas the observation of this lava dome at Lascar emphasizes the value of remote-sensing techniques in monitoring remote volcanoes, we stress that there are many current limitations, not least of which is the 16-day repeat period of the Landsat satellite used in our studies and the vagaries in behaviour of individual volcanoes. Future generations of remotesensing satellites, such as those forming part of NASA's Earth Observing System will offer much greater scope for volcanological studies. Detailed plans for these are already in hand. Initially, we believe that these techniques are valuable tools for monitoring volcanoes; prediction of the eruption of an individual volcano will remain difficult, ideally involving data from as many different sources as possible, both terrestrial and space-borne.

Lunar and Planetary Institute

P.W. FRANCIS

Houston, Texas 77058, USA

MS 183-501,

L.S. GLAZE

Jet Propulsion Laboratory,

Pasadena, California, USA

D.A. ROTHERY

Department of Earth Sciences,

Open University,

Milton Keynes MK7 6AA, UK

Impacts and the origin of life

SIR-The point in time at which life could first appear on Earth through chemical evolution within a time interval between impact events was considered by K.A. Maher and D.J. Stevenson (Nature 331, $612-614 ; 1988$ ) for assumed chemical or prebiotic evolution times of $10^{5}-10^{7}$ years. We would like to point out an error that leads to an incorrect estimate of this time. In Maher and Stevenson's model, the number of events per unit time was derived for each of four classes of impact effects that were considered to be adverse to the evolutionary process. The reciprocal of these values are the time periods between the impact events: $T_{c}$ is the time required to obliterate the surface by crater overlap; $T_{\mathrm{e}}$ is the time to cover the surface by 3 metres of ejecta; $T_{\mathrm{w}}$ is the time between impacts that frustrate life on a global scale by causing climatic disruption, sterilization of the surface or sterilization of the entire planet; and $T_{\mathrm{b}}$ is the time taken to obliterate the ocean bottom by crater overlap. These time periods were given by

$$
\begin{gathered}
T_{\mathrm{c}}=1.0 \times 10^{11}\left[f(t)^{-1}\right]\left[\left(D_{\max } / 1 \mathrm{~km}\right)^{0.2}-\right. \\
\left.\left(D_{\min } / 1 \mathrm{~km}\right)^{0.2}\right]^{-1} \mathrm{yr} \\
T_{\mathrm{e}}=1.0 \times 10^{11}\left[f(t)^{-1}\right]\left[\left(D_{\text {e, max }} / 1 \mathrm{~km}\right)^{0.51}-\right. \\
\left.\left(D_{\mathrm{e}, \min } / 1 \mathrm{~km}\right)^{0.51}\right]^{-1} \mathrm{yr} \\
T_{\mathrm{w}}=250\left[f(t)^{-1}\right]\left[\left(D_{\min } / 1 \mathrm{~km}\right)^{2.8} \mathrm{yr}\right. \\
T_{\mathrm{b}}=5.0 \times 10^{10}\left[f(t)^{-1}\right]\left[\left(D_{\max } / 1 \mathrm{~km}\right)^{0.2}\right. \\
\left.\left(D_{\min } / 1 \mathrm{~km}\right)^{0.2}\right]^{-1} \mathrm{yr}
\end{gathered}
$$

The proportionality constants in these equations consist of the products of various constants associated with impact parameters and a crater-production constant $k$ corresponding to eight times the crater production rate on the Moon. The function $f(t)$ is an exponential decay function that allows for the changing flux of impactors early in planetary history. This function is $f(t)=1+\exp \left[\left(t-t_{0} / T\right]\right.$, where $t$ is the time measured backwards from the present, $t_{0}=3,400$ million years and $T=70$ million years. $D_{\text {min }}$ and $D_{\max }$ are the minimum and maximum diameters of crater sizes contributing to the impact effect being considered.

In deriving equation (3), Maher and Stevenson consider the time interval between impacts that are just large enough to frustrate life on a global scale. For any particular global-impact effect, however, a range of crater diameters, from those just large enough to cause the effect up to the size just large enough to cause the next higher level of destruction, should have been used in determining the expected time interval between these events. That is, the time interval between events should be calculated from the product of the surface area of the Earth and the integral of the incremental number density evalua- ted over the range of crater sizes capable of causing that effect.

We obtain

$$
\begin{gathered}
T_{\mathrm{w}}=1,400 \mathrm{f}(t)^{-1}\left[\left(1 \mathrm{~km} / D_{\min }\right)^{1.8}-\right. \\
\left(1 \mathrm{~km} / D_{\max }\right)^{1.8]^{-1}}
\end{gathered}
$$

for the time between impacts that frustrate life on a global scale. We used this equation, rather than equation (3), to calculate the time intervals between global events. $D_{\min }$ and $D_{\max }$ are 55 and $265 \mathrm{~km}, 265$ and $850 \mathrm{~km}$, and 850 and $2,600 \mathrm{~km}$, for climatic disturbances, surface sterilization and planetary sterilization, respectively.

When the time period between events disruptive to chemical and early biotic evolution became greater than the time required to evolve life, life could first have appeared on Earth. Maher and Stevenson assumed that life formed in $10^{5}-10^{7}$ years and calculated the point in time at which impact events became infrequent enough for life to form. With our revised equation (5) instead of (3), life could first appear at times more recent than those reported by Maher and Stevenson. For example, if large single events with energy of the order of $10^{34} \mathrm{erg}$, assumed to have been capable of 'sterilizing' the entire planet, were required to frustrate development of life, Maher and Stevenson find that life could have first originated between 4,100 and 4,300 million years ago, whereas we calculate this time interval to be 3,700 4,000 million years ago. Also, using equation (5) instead of equation (3) changes the sequence of times at which life can first appear uninterrupted by each of the impact effects. Using equation (3), for example, life appears more recently if it can be interrupted by crater obliteration rather than by planetary sterilization, whereas, using equation (5), the reverse is true. This reordering of the sequence of times at which life can first appear constitutes a significant difference between the results of Maher and Stevenson and those presented here.

\section{Solar System Exploration Branch,}

VERNE R. OBERBECK GUY FOGLEMAN

SETI Institute,

Mail Stop 239-12,

NASA Ames Research Center, Moffett Field,

California 94035 ,

USA

\section{Scientific Correspondence}

Scientific Correspondence is intended to provide a forum in which readers may raise points of a scientific character. They need not arise out of anything published in Nature. In any case, priority will be given to letters of less than 500 words and five references. 